\title{
Detection of Biofilm Forming Ability of Bacterial Isolates from Contact Lenses and their Accessories
}

\section{Sameen Naz Zuberi ${ }^{*}$ and Sayyeda Ghufrana Nadeem}

Department of Microbiology, Jinnah University for Women, Nazimabad, Karachi, Pakistan

"Corresponding author: Sameen Naz Zuberi, Department of Microbiology, Jinnah University for Women, Nazimabad, Karachi, Pakistan, E-mail: sameen.zuberi@live.com

Received date: July 25, 2017; Accepted date: September 26, 2017; Published date: October 04, 2017

Copyright: (c) 2017 Zuberi SN, et al. This is an open-access article distributed under the terms of the creative commons attribution license, which permits unrestricted use, distribution, and reproduction in any medium, provided the original author and source are credited.

\begin{abstract}
In modern era the usage of contact lens is increased in youngsters especially in females with a high risk of ocular infections. In current research bacteriological analysis and bio-film forming ability of 22 contact lens accessories samples (Contact lenses, contact lens storage kit and contact lens solution) is studied. The isolated bacteria includes Corynebacterium spp, S. aureus, coagulase negative Staphylococcus, Bacillus spp. and Streptococcus spp. Bio-film are the main cause of bacterial infection. The bio-film forming ability of these bacterial isolates is studied by Congo red agar method and tube method. Best results were observed in Test tube method. The results initiate to continue further researches on the pathogenesis of bacteria as well as guide patients with proper contact lens procedures will hopefully decrease the incidence of ocular infections. Modern approaches for bio-film prevention and control will help in elimination of different diseases. The main objective of the research is to study the contact lens accessories isolated pathogens and their bio-film forming ability.
\end{abstract}

Keywords: Biofilm; Contact lens; Ocular infections; Tube method; Congo red agar

\section{Introduction}

Contact lenses play principal role in developing ocular infection [1] and a significant factor for developing ocular infections in contact lens users is the microbial contamination in their lens care system which includes the ophthalmic solution, lens cases and lenses used by the contact lens wearer [2]. The pathogenic property of microbes of forming biofilm on contact lens surfaces plays a crucial role in developing contact lens related eye infections [1].

\section{Biofilm production, characteristic of pathogenic bacteria}

A biofilm can be define as aggregate of microbes in which cells stick to each other and to a surface. These adherent cells are frequently embedded within a self-produced matrix of extracellular polymeric substance (EPS) [3]. Biofilm is a survival strategy of microbes in which they are protected against antibacterial chemical, environmental bacteriophages and phagocytes [4].

Gram +ve and Gram -ve bacteria have the abilty to produce biofilm such as Staphylococcus aureus, Staphylococcus epidermidis, Streptococcus viridans, Escherichia coli, Enterococcus faecalis, Klebsiella pneumonia, Proteus mirabilis and Pseudomonas aeruginosa [5].

\section{Steps in Biofilm Production}

\section{Stage 1: adhesion}

In first stage bacteria reach the stratum where they will adhere. If bacteria is non-motile the transport will be random. Suspending fluid flow results in Brownian motion of an organism. As compare to that the motile microbes attracts towards the stratum which show chemo tactic, aerostatic or photo tactic response. Once the bacteria reach at its point it will adhere to it. In natural environment microbes rarely adhere to stratum itself. Each time it is coated with a layer of molecules called as "conditioning film" on which microbes usually adheres.

\section{Stage 2: co-adhesion}

Now Bacteria start colonizing and synthesizing Extra cellular matrix molecules (polysaccharides) The multiplication of the attached bacteria and the adherence of other microbes on them is known as coadhesion. In this stage the synthesis of matrix molecules is important.

\section{Stage 3: maturation and detachment}

In this stage the attached organisms grow further forming mature biofilm. The final form is frequently introduced to powerful mechanical and hydrodynamic forces which results in detachment of biofilm or some parts of it (Figure 1) [6].

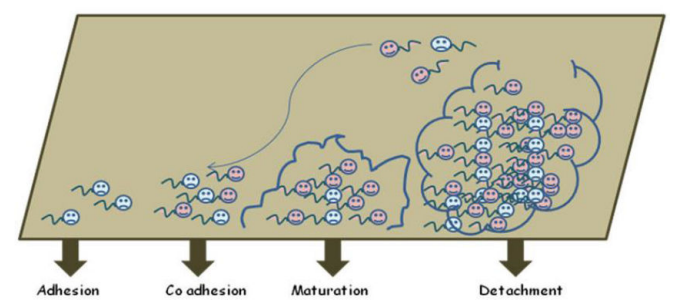

Figure 1: Stages in Biofilm production. 
Page 2 of 6

\section{Reason behind resistivity of bacteria}

Some of the reasons that are believed to the capability of biofilm to bear high concentration of antimicrobial agents include:

1. Binding of the antimicrobial agent to the extracellular matrix of the biofilm, thereby limiting its penetration.

2. Inactivation of the antimicrobial agent by enzymes trapped in the biofilm matrix.

3. The reduced growth rate of bacteria in biofilm renders them less susceptible to the antimicrobial agent.

4. The altered microenvironment within the biofilm can reduce the activity of the agent.

5. Altered gene expression by organisms within the biofilm can result in a phenotype with reduced susceptibility to the antimicrobial agent [7].

\section{Aim}

The aim of this research is to study contact lens accessories isolated microbes and their biofilm forming ability.

\section{Methodology}

\section{Sampling}

The study is conducted in a duration of 1 August 2014 to 31 January 2015. The samples were used by Jinnah university students of 18-23 years of age group the lenses were not frequently washed with lens care solution instead of that tap water was used for washing.

22 samples were taken randomly which include 8 samples of contact lens storage cases, 8 samples of contact lens solution and 6 samples of contact lenses.

\section{Isolation from contact lenses}

The contact lenses were swabbed with sterile cotton swab moistened with sterile normal saline solution. Each swab is then streaked on nutrient agar and incubated overnight at $37^{\circ} \mathrm{C}$.

\section{Isolation from contact lens solution}

One drop each of the contact lens solution was inoculated directly from the container onto nutrient agar. Inoculum was then streaked on the surface of the agar and incubated for $24 \mathrm{~h}$ at $37^{\circ} \mathrm{C}$.

\section{Isolation from lens storage case}

$2 \mathrm{ml}$ of sterile saline was taken in test tube. Cotton swab was dipped in saline and swabed on empty lens storage case. This was streaked on nutrient agar and incubated for $24 \mathrm{~h}$ at $37^{\circ} \mathrm{C}$.

The cultures in which growth is not detected within $48 \mathrm{~h}$ are considered as negative. The identification of bacterial cultures was done by using Gram's staining, spot test (catalase test, co-agulase test and oxidase test) and selective media (Potassium telluride agar, Mannitol salt agar, Dnase agar and Blood agar) and MHA.

\section{Detection of biofilm production}

Biofilm production can be done by variety of methods. We have followed following two methods to study biofilm from contact lens isolates.

\section{Tube method}

TSBglu was inoculated with loopful of microorganisms from overnight culture plates and incubated for 24 hours at $37^{\circ} \mathrm{C}$.

Tubes were decanted and washed with PBS (pH7.3) and dried. Dried tubes were stained with crystal violet $(0.1 \%)$. Excess stain was removed and tubes were washed with deionized water.

Tubes were then dried in inverted position and observed for biofilm formation [8].

\section{Congo red agar method}

BHI broth supplemented with 5\% sucrose and Congo red.

Medium was composed of:

BHI (37 gm/L)

Sucrose $(50 \mathrm{gm} / \mathrm{L})$

$\operatorname{Agar}(10 \mathrm{gm} / \mathrm{L})$

Congo red stain $(0.8 \mathrm{gm} / \mathrm{L})$

Congo red was prepared as concentrated aqueous solution and autoclaved at $121^{\circ} \mathrm{C}$ for 15 mins separately from other medium constituents and was added when the agar had cooled to $55^{\circ} \mathrm{C}$.

Plates were inoculated and incubated for $24-48 \mathrm{~h}$ at $37^{\circ} \mathrm{C}$ [8].

\section{Results and Discussion}

Normal conjunctival flora is either exogenous or endogenous in origin, which can be contracted from environment, physical contact or unhygienic habits of people. One of the physical contact is the use of contact lenses and also the unhygienic maintenance of the lenses [2].

22 contact lens accessories samples were subjected to bacteriological analysis. Following bacterial isolates were isolated from the samples (Tables 1-4).

\begin{tabular}{|l|l|}
\hline Sample & Organism \\
\hline Sample 1 & Corynebacterium spp \\
\hline Sample 2 & Corynebacterium spp \\
\hline Sample 3 & Staphylococcus aureus \\
\hline Sample 4 & Bacillus subtilus \\
\hline Sample 5 & Bacillus cereus \\
\hline Sample 6 & Bacillus subtilus \\
\hline Sample 7 & Bacillus cereus \\
\hline
\end{tabular}

Table 1: Isolation from lens storage case.

Lens contamination is probably the greatest risk factor for corneal infection, the sources and factors leading to the contamination of microbes on lenses are of great interest [9]. 
Citation: Zuberi SN, Nadeem SG (2017) Detection of Biofilm Forming Ability of Bacterial Isolates from Contact Lenses and their Accessories. J

Page 3 of 6

\begin{tabular}{|l|l|}
\hline Sample & Organism \\
\hline Sample 1 & Coagulase -ve Staphylococcus \\
\hline Sample 2 & Staphylococcus aureus \\
\hline Sample 3 & Staphylococcus aureus \\
\hline Sample 4 & Bacillus cereus \\
\hline Sample 5 & Staphylococcus aureus \\
\hline Sample 6 & Corynebacterium spp \\
\hline Sample 7 & Corynebacterium spp \\
\hline Sample 8 & Staphylococcus aureus \\
\hline Sample 9 & Staphylococcus aureus \\
\hline
\end{tabular}

Table 2: Isolation from contact lens solution.

In this study we have isolated 22 Gram positive bacteria from contact lens kit which include Corynebacterium specie, Staphylococcus aureus, Coagulase negative Staphylococci, Bacillus spp, and Streptococcus spp.

About 6 isolates are of Staphylococcus aureus, 8 are of Corynebacterium spp, 6 are of Bacillus spp, 1 of coagulase negative Staphylococcus and 1 is of Streptococcispp.

\begin{tabular}{|l|l|}
\hline Sample & Organism \\
\hline Sample 1 & Corynebacterium spp \\
\hline Sample 2 & Corynebacterium spp \\
\hline Sample 3 & Corynebacterium spp \\
\hline Sample 4 & Bacillus subtilus \\
\hline Sample 5 & Streptococcus spp \\
\hline Sample 6 & Corynebacterium \\
\hline
\end{tabular}

Table 3: Isolation from contact lenses.

In previous study, it was reported that $P$. aeruginosa was the most common contaminant of contact lenses. In the present study Corynebacterium was isolated from contact lens kit in high frequency.

According to Rahim et al., it was reported that $12.3 \%$ S. aureus was found in contact lens care systems of asymptomatic subjects, comparing with this study $27.27 \%$ S.aureus was isolated from contact lens kit.

In the same study among Bacillus species $16 \%$ were isolated from contact lens care system however we have isolated $27 \%$ of Bacillus species from contact lens kit. Bacillus is commonly present in our environment.

\begin{tabular}{|l|l|l|l|l|}
\hline Organism & $\begin{array}{l}\text { Gram } \\
\text { stain }\end{array}$ & $\begin{array}{l}\text { Spore } \\
\text { formation }\end{array}$ & $\begin{array}{l}\text { Cell } \\
\text { shape }\end{array}$ & Arrangement \\
\hline Bacillus & Gram +ve & $\begin{array}{l}\text { Terminal, } \\
\text { center }\end{array}$ & Rod & Chain \\
\hline S. aureus & Gram +ve & Absent & Cocci & Bunches \\
\hline $\begin{array}{l}\text { Coagulase -ve } \\
\text { staph }\end{array}$ & Gram +ve & Absent & Cocci & Bunches \\
\hline Corynebacterium & Gram +ve & Absent & Rod & Chinese letter like \\
\hline Streptococci & Gram +ve & Absent & Cocci & Chain \\
\hline
\end{tabular}

Table 4: Microscopic characteristics of contact lens accessories isolates.

E. coli were also frequently found in contact lens storage case, $12.4 \%$. It may be due to lack of personal hygiene and contaminated home water supply but in our study E. coli, Pseudomonas and any other Gram negative organism was not isolated this may be due to the proper take care of hygiene among contact lens users (Table 5).

\begin{tabular}{|l|c|c|c|}
\hline Organism & Catalase & Coagulase & Oxidase \\
\hline Bacillus & $+\mathrm{ve}$ & - & -ve \\
\hline S. aureus & $+\mathrm{ve}$ & $+\mathrm{ve}$ & $-\mathrm{ve}$ \\
\hline Coagulase -ve staph & $+\mathrm{ve}$ & $-\mathrm{ve}$ & $-\mathrm{ve}$ \\
\hline Corynebacterium & $+\mathrm{ve}$ & - & $-\mathrm{ve}$ \\
\hline Streptococci & $-\mathrm{ve}$ & - & $-\mathrm{ve}$ \\
\hline
\end{tabular}

Table 5: Biochemical characteristics of contact lens accessories isolates.

\begin{tabular}{|c|c|c|c|c|c|}
\hline Organism & Nutrient agar & Blood agar & MSA & $\begin{array}{l}\text { Potassium tellurite } \\
\text { agar }\end{array}$ & DNAse \\
\hline Bacillus & Irregular off-white colonies & Alpha-hemolysis & - & - & $-v e$ \\
\hline S. aureus & Yellow small colonies & Alpha-hemolysis & Yellow fermented colonies & - & $-v e$ \\
\hline Coagulase-ve staph & Yellow small colonies & Alpha-hemolysis & Yellow fermented colonies & - & $-v e$ \\
\hline Corynebacterium & Small pin pointed colonies & Alpha-hemolysis & - & Brown color colonies & -ve \\
\hline Streptococci & Mucoid colonies & Beta-hemolysis & - & - & $-v e$ \\
\hline
\end{tabular}

Table 6: Cultural characteristics of contact lens accessories isolates.

According to PR et al. [10] Streptococcus pneumoniae was an uncommon isolate and was recovered from only one of the 3,763 conjunctival samples. The presence of $S$. pneumoniae on the contact lens was associated with a significant risk of development of corneal 
infiltrates, however only $1 \%$ of Streptococcus species was isolated in our study (Table 6).

Lid and conjunctival bioburden are associated with contact lens bioburden; however, the directions of the associations are unclear. There are multiple possibilities that explain these relationships. The conjunctiva or lid may serve as the source of contamination to the lens, Hart et al. [11], Wilcox et al. [12]. Contact lens wear may disrupt the ecology of the ocular surface by altering the balance of the normal micro biota. For example, contact lens usage affects the balance between staphylococci and Corynebacterium in conjunctival micro biota and causes the advance of staphylococci [13]. In this study $36 \%$ of Corynebacterium species has been isolated.

According to Loretta [9] the most likely route for contamination of contact lenses is from the skin to the lens. The evidence for this is that the majority of isolates found on contact lenses in their study were coagulase negative staphylococci which are normal, ubiquitous skin microbiota but in our study only 1 coagulase negative Staphylococci was isolated.

The Staphylococcus aureus, coagulase negative Staphylococcus, Streptococcus spp, Corynebacterium spp, are the normal flora of Skin, conjunctiva, nose and pharynx but Bacillus is present in our environment and is not a normal flora of human body (Figure 2).

The human flora can contaminate contact lens kit easily as compared to any other bacteria.

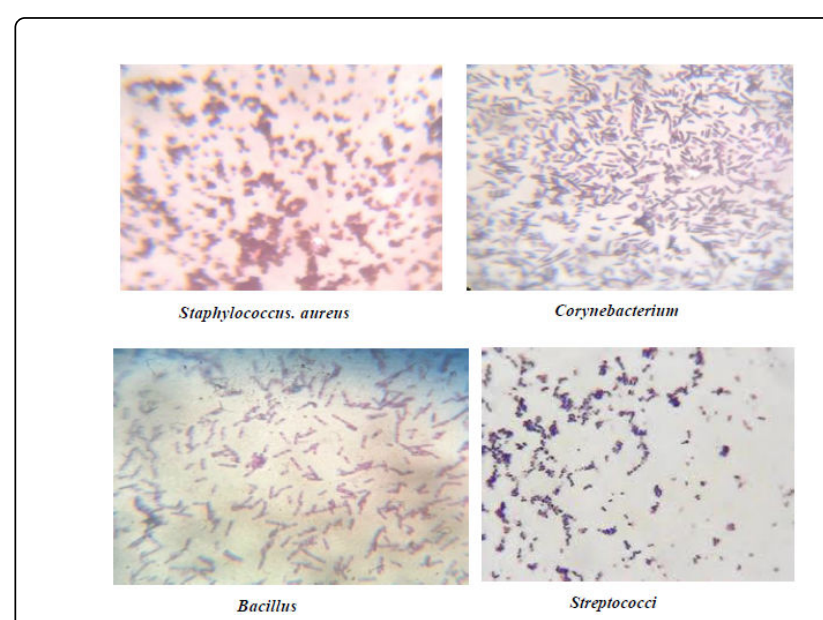

Figure 2: Microscopic representation of isolated bacteria.

Microorganisms require some nutrition for the formation of biofilms like iron source, glucose, glutamate, citrate, malate, mannitol, xylose, glycerol, sucrose. For the production of biofilm we have used glucose and sucrose as a nutrition factor (Table 7).

There are variety of methods available to study the production of biofilm. We performed 2 methods to study this property of microorganism which include tube method and Congo red agar method.

In tube method 14 isolates out of 22 produced biofilm. TSBglu (TSB $66 \%$ supplemented with $0.2 \%$ glucose $\mathrm{pH} 7.8$ ) is used as a source of nutrition (Figure 3).

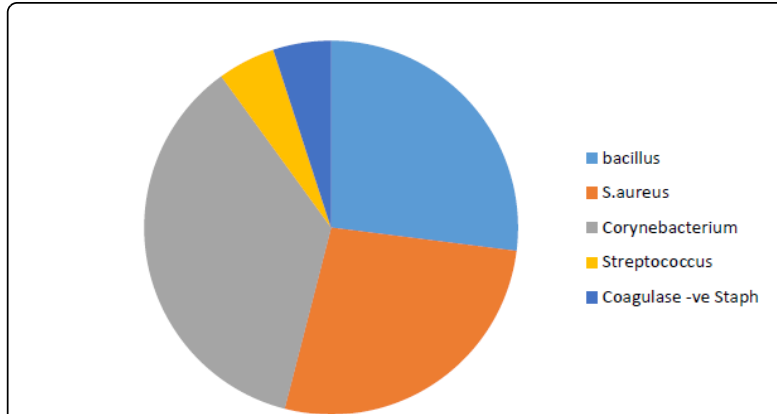

Figure 3: Frequency of isolates from the contact lens accessories.

Out of 22 isolates 14 isolates showed positive results in tube method while in Congo red agar 21 isolates showed pink colonies which indicate weak slime layer production.

\begin{tabular}{|c|c|}
\hline Organism & Biofilm formation \\
\hline Corynebacterium spp & + \\
\hline Corynebacterium spp & + \\
\hline Staphylococcus aureus & + \\
\hline Bacillus subtilus & - \\
\hline Bacillus cereus & - \\
\hline Bacillus subtilus & - \\
\hline Bacillus cereus & - \\
\hline Staphylococcus saphrophyticus & + \\
\hline Staphylococcus aureus & - \\
\hline Staphylococcus aureus & - \\
\hline Bacillus cereus & - \\
\hline Staphylococcus aureus & ++ \\
\hline Corynebacterium & + \\
\hline Corynebacterium & ++ \\
\hline Staphylococcus aureus & + \\
\hline Staphylococcus aureus & + \\
\hline Corynebacterium & + \\
\hline Corynebacterium & + \\
\hline Corynebacterium & + \\
\hline Bacillus subtilus & - \\
\hline Streptococcus & + \\
\hline Corynebacterium & + \\
\hline
\end{tabular}

Table 7: List of contact lens kit isolates producing biofilm in tube. ++ : moderate biofilm producers, + : weak biofilm producers, -: biofilm is absent. 
Citation: Zuberi SN, Nadeem SG (2017) Detection of Biofilm Forming Ability of Bacterial Isolates from Contact Lenses and their Accessories. J

Page 5 of 6

Biofilm formation was considered positive when a visible film lined the wall and bottom of the tube. Ring formation at the liquid interface was not indicative of biofilm formation (Figure 4) [8].

Strong biofilm producing bacteria showed the high adherence to the wall of the tubes and the bottom of the tubes. Moderate biofilm producing bacteria showed less adherence while non-biofilm producing bacteria showed no adherence to the wall and the bottom of the test tubes. Studies also suggest that biofilm formation also depends strongly on the environmental conditions $[14,15]$.

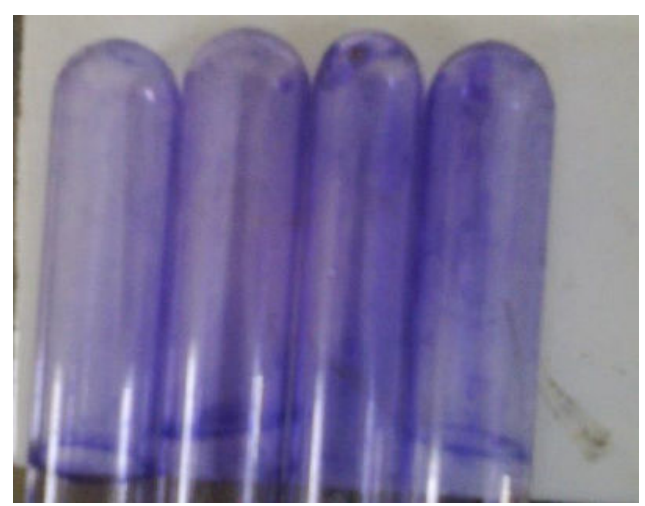

Figure 4: Biofilm production in test tubes.

The CRA plate test uses a solid medium, namely Congo red agar This method allows for the direct analysis of the colonies and the identification of slime-forming strains and non-slime-forming strains. This is not a quantitative assay because it is based on a subjective chromatic evaluation. The strains that score positive during the test have black spikes on red colonies which remain unchanged in color (Table 8).

\begin{tabular}{|l|l|}
\hline Organism & Biofilm formation \\
\hline Corynebacterium spp & - \\
\hline Corynebacterium spp & + \\
\hline Staphylococcus aureus & + \\
\hline Bacillus subtilus & + \\
\hline Bacillus cereus & + \\
\hline Bacillus subtilus & + \\
\hline Bacillus cereus & + \\
\hline Staphylococcus saphrophyticus & + \\
\hline Staphylococcus aureus & + \\
\hline Staphylococcus aureus & + \\
\hline Bacillus cereus & + \\
\hline Staphylococcus aureus & + \\
\hline Corynebacterium & + \\
\hline Corynebacterium & + \\
\hline Staphylococcus aureus & + \\
\hline
\end{tabular}

\begin{tabular}{|l|l|}
\hline Staphylococcus aureus & + \\
\hline Corynebacterium & + \\
\hline Corynebacterium & + \\
\hline Corynebacterium & + \\
\hline Bacillus subtilus & + \\
\hline Streptococcus & + \\
\hline Corynebacterium & + \\
\hline
\end{tabular}

Table 8: List of contact lens kit isolates producing biofilms on CRA. (no colonies): no biofilm production, + (Pink colonies): weak slime layer production, ++ (Black colonies): Biofilm production.

Positive result was indicated by black colonies with a dry crystalline consistency. Weak slime producers usually remained pink, though occasional darkening at the centers of colonies was observed. A darkening of the colonies with the absence of a dry crystalline colonial morphology indicated an indeterminate result [8].

The CRA result don't show any correlation with tube method. All the stains showed pink colonies on 24-48 h of incubation (Figure 5).

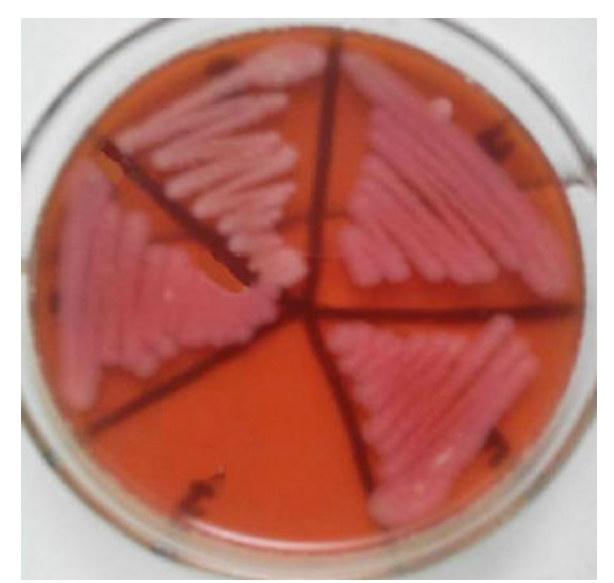

Figure 5: Pink colonies showing weak slime layer production on Congo red agar by contact lens kit isolates.

As compared to results with Mathur, tube Method showed strong biofilm forming isolates and total $18(11.8 \%)$ isolates were picked up as strong and $45(29.6 \%)$ were moderate biofilm producers. However, it was difficult to discriminate between moderate and weakly biofilm producing isolates but in this study 14 isolates have produced biofilm out of which 2 isolates produced moderate biofilm and rest of the isolates produced weak biofilm.

In CRA method out of eight positive isolates, three (1.97\%) displayed black colonies with no dry crystalline morphology, and five (3.2\%) displayed dry crystalline morphology, however in this study out of 22 isolates 21 isolates produced pink colonies.

As compare to other results the CRA plate method for testing biofilms production, showed that only four isolates (3.4\%) produced black crystalline morphology while 111 (96.5\%) gave orange-red colonies. The CRA plate method is not recommended as a medium for 
biofilm production. Similar results have been reported by other authors $[8,15,16]$.

In biofilm producing experiment we can conclude that tube method is more accurate the CRA method to study the property of biofilm as well as high nutrition value is needed for the production of biofilm.

\section{Conclusion}

Contact lens wearers are at high risk of getting ocular infections because of the contamination of contact lenses contact lens storage cases and contact lens solution by microbes. People should be educated for proper eye care to avoid chances of getting infection.

Continued research on the pathogenesis of bacteria as well as patient education on proper contact lens procedures will hopefully decrease the incidence of ocular infections. Many researchers in the fields of medical, food, water, and environmental microbiology initiated to investigate microbiologic processes from a biofilm perspective. Fresh strategies for biofilm prevention and control will help in prevention of different diseases.

\section{References}

1. Randler C, Matthes R, McBain AJ, Giese B, Fraunholz M, et al. (2010) A three-phase in-vitro system for studying Pseudomonas aeruginosa adhesion and biofilm formation upon hydrogel contact lenses. BMC Microbiol 10: 282

2. Rahim N, Bano H, Naqvi BS (2008) Bacterial Contamination among Soft Contact Lens Wearer. Pak J Ophthalmol 24: 93-96.

3. Verma N, Bansal MC, kumar V (2010) Comparative studies on biofilm development by Aspergillus niger on polyester sheet and muslin cloth. J Biochem Tech 2: 187-188.

4. Arampatzi SI, Giannoglou G, Diza E (2011) Biofilm formation: A complicated microbiological process. Aristotle Uni Med 38: 21-29.
5. Rewatkar AR, Wadher BJ (2013) Staphylococcus aureus and Pseudomonas aeruginosa-Biofilm formation Methods. J Pharm Biol Sci 8: 36-40.

6. Sekhar S, Ohri M, Chakraborti A (2011) Biofilms: An Evolving and Universal Evasive Strategy of Bacterial Pathogens. Tech Educ Topic in Appl Microbiol and Microbial Biotech. Formatex Press pp. 855-859.

7. Wilson M (2001) Bacterial Biofilms and Human Disease. Sci Prog 84: 235-254.

8. Mathur T, Singhal S, Khan S, Upadhyay DJ, Fatma T, et al. (2006) Detection of biofilm formation among the clinical isolates of staphylococci: An evaluation of three different screening methods. Indian J Med Microbiol 24: 25-29.

9. Szczotka-Flynn LB, Bajaksouzian S, Jacobs MR, Rimm A (2009) Risk Factors for Contact Lens Bacterial Contamination During Continuous Wear. Optom Vis Sci 86: 1216-1226.

10. Sankaridurg PR, Sharma S, Willcox M, Sweeney DF, Naduvilath TJ, et al. (1999) Colonization of hydrogel lenses with Streptococcus pneumoniae: risk of development of corneal infiltrates. Cornea 18: 289-295.

11. Hart DE, Hosmer M, Georgescu M, Farris RL (1996) Bacterial assay of contact lens wearers. Optom Vis Sci 73: 204-207.

12. Willcox MD, Power KN, Stapleton F, Leitch C, Harmis N, et al. (1997) Potential sources of bacteria that are isolated from contact lenses during wear. Optom Vis Sci 74: 1030-1038.

13. Kozer-Bilgin L, Demir N, Altan-Yaycioglu R (1999) Microbiological evaluation of contact lenses and contact lens disinfection solutions in an asymptomatic population and in medical personnel. CLAO J 25: 228-232.

14. Ammendolia MG, Rosa RD, Montanaro L, Arciola CR, Baldassarri L (1999) Slime production and expression of slim-associated antigen by staphylococcal clinical isolates. J Clin Microbiol 37: 3235-3238.

15. Taj Y, Essa F, Aziz F, Kazmi SU (2012) Study on biofilm forming properties of clinical isolates of Staphylococcal aureus. J Infect Dev Ctries 5: 403-409.

16. Knobloch JK, Horstkotte MA, Rhode H, Mack D (2002) Evaluation of different detection methods for biofilm formation in Staphylococcus aureus. Med Microbiol Immunol 191: 101-106. 